\title{
Conversation on statistics without borders, (17 May 2015) between Cathy Furlong (Chair) and Katherine Condon and Kirsten West (JAIOS)
}

\author{
E-mail: kwestiaos@gmail.com
}

\author{
Interviewers: We would like to start our \\ conversation by talking about the history of \\ Statistics Without Borders (SWB), how it \\ developed, its mission, some of the past and \\ current projects and then we are also curious to \\ learn about your experiences with SWB.
}

In 2005, the American Statistical Association (ASA) started a group called "Special Interest Group on Volunteerism". At the 2008 Joint Statistical Meeting (JSM), a panel session entitled "Statisticians Speaking Out and Reaching Out on Global Health" was on the program and sparked a conversation between Gary Shapiro and Fritz Scheuren, which eventually resulted in the formation of Statistics Without Borders (SWB). SWB had four co-founders: Steve Pierson, Gary Shapiro, Fritz Scheuren and Jim Cochran.

The group on volunteerism gradually declined whereas SWB continued to grow. In 2010, SWB became an outreach organization of the ASA, and it started drafting its first charter. The group had about 130 members that year. Now, in 2015, there are about 1,400 members - all volunteers.

Statistics Without Borders provides free statistical consulting to organizations and government agencies, particularly from developing nations. These organizations and agencies do not have resources for statistical services. In support of non-partisan and secular activities, SWB promotes the use of statistics to improve the health and well-being of all people. The vision is to achieve and implement best statistical practices in the services of others.

The definition of what constitutes a project has developed over the years. Last year at the 2014 JSM SWB Business Meeting, Gary Shapiro and I introduced two amendments to the Charter. One of amendments was to extend the definition of a project from global health to include "... the use of statistics to improve the health and well-being of all people". SWB will work with governments and non-profit organizations that need statistical help and cannot afford a statistician of their own. SWB is an outreach committee of the American Statistical Association; SWB will work with organizations about the value of statisticians and at the same time as well as working with an organization or an agency to solve a statistical problem, SWB volunteers show the benefits of having statistical help and encourage the organization to hire a statistician. SWB has been successful in this goal by posting positions for statisticians for client organizations.

The earthquake in Nepal this year is an example of a situation where SWB stepped in. One of the humanitarian agencies wanted to join databases, but did not know how to accomplish the task. There was no statistical analysis involved. People on the ground simply needed a clean dataset that could help them do their work.

Different organizations have knowledge about 'combining' databases, but statisticians bring in a perspective that can help in a crisis, such as the one in Nepal 
after the earthquake. Statisticians look at the situation from a multi-purpose perspective. For example, when I look at a dataset as a statistician, I ask the question, "What do you want to do with this dataset?" "What variables do I need on this dataset?"

\section{Interviewers: Where do these datasets reside?}

In the case of Nepal, we learned that the Nepal government has excellent demographic datasets. When the e-mail request came out on the Digital Humanitarian Network (DHN), it was a request for help with organizing datasets. I took a look initially at these datasets and it was overwhelming. It was overwhelming and fabulous at the same time, because there was so much information. There was all this information in different datasets, for different districts and different EXCEL tabs. Information was needed from each tab, but it had to be combined in order to be of any use for the people working on the ground.

SWB can also provide a perspective after the crisis. As an outreach organization, SWB has worked with groups after the crisis to see the limitations of a certain way of organizing the data. This is where SWB can step in because our statisticians have experience and can help. Three SWB statisticians/volunteers worked on the Nepal project.

Statistics Without Borders continues to grow. Not only has our memberships grown. The projects have grown and the types of projects we get involved with are changing.

\section{Interviewers: How did you learn about the organization? How did you get involved?}

I retired from teaching in 2008. I knew I wanted to pursue a career in statistics but did not know what area/subject I was interested in. I decided to do volunteer work for many non-governmental organizations. Mary Gray, who was my advisor at American University, suggested I get involved in both the American Association for the Advancement of Science-On-Call Scientists and Stat-Aid; both organization work on human rights projects. These experiences resulted in me being introduced to SWB at the 2011 JSM SWB Business meeting. At the SWB Business meeting, an e-mail list was circulated and it was suggested that anyone in attendance not on the list put his or her name on it. Justin Fisher, New Project Chair, was looking for someone to work with him. My name was suggested and I started working with him. Later on, Justin became chair of SWB and I became the New Project Chair. There was no planning on my part; my involvement just worked out that way.

Upon reflection, I see when one is open, listening and meeting people; one begins to recognize those individuals who are great mentors. One may not realize this at the time, but you know the people you are meeting are really good at what they do. Moreover, you just know that if these people suggest something, that you should follow that lead and do it. Mary Gray, my advisor at American University, and Fritz Scheuren, were some of these people for me. I knew both individuals are highly regarded in their field. I did not always understand what both suggested I do; I just did it.

It all sort of flows together. People who are interesting and interested in helping to develop other people's skills. Somehow, these people have that bit of natural connectivity and you are looking for those types of people, for those people who are a little curious, who need to or want to move on to explore things. For me, there was no plan; I had no idea what I was getting involved in. It just kind of falls in your lap, you find it interesting, and you start getting involved. You know you are doing the right thing because it feels right and you do not have to think about it.

People have 1 said to me "Gosh, you spend so much time on this" and yet, I say, "It is so fascinating." Time is immaterial. Can you imagine? I get to talk to people around the world. I have the opportunity to talk to them about what projects they want to do and why they want to do them. What they need. Why they need it. I have had the opportunity to work with so many different people and see how so many talented people use their knowledge and technical skills. By working with people from around the world, you begin to understand we just want to work together to solve whatever problem there is to solve; it is amazing how we all can get along.

\section{Interviewers: Tell us about the first SWB project you worked on.}

I did not really work on a specific SWB project until I was New Projects Chair. I actually organized projects before I participated in one. Once I became Chair of the New Projects Committee, probably less than a year after I became involved, I became so busy with organizing projects that I had no time to participate in any project, although many of them interested me. 
In the Fall of 2012, Gary Shapiro, then Past Chair and one of the co-founders, suggested I attend a daylong conference in DC on the Digital Humanitarian Network (DHN). Gary thought it would be a good idea to partner with this organization. I knew nothing about working with humanitarian organizations and my technology understanding is not that strong, but I was willing to try. The Digital Humanitarian Network (DHN) is a group of non-profit and volunteer organizations under the umbrella of the United Nations that work together during a humanitarian crisis (e.g., typhoons, earthquakes, hurricanes) to supply the necessary information to humanitarian efforts on the ground.

SWB's first DHN collaboration was a post-crisis Hurricane Sandy project for Stand-By Task Force (SBTF). Wanting to build the DHN partnership during a crisis, I volunteered to lead a joint SWB and Stand-By Task Force during the Typhoon Haiyan crisis. I gained a lot of respect for the DHN organizations and the work they do during a crisis from that experience. However, it also reinforced I could not work on a project and give five or more hours a week as Chair of the New Projects Committee and do both tasks successfully.

About a year and a half into my tenure as New Projects Chair, I started to write down how to start a project; in other words, I started a manual or guidelines on how to organize a project, how to get and organize volunteers. It was all a learning experience.

\section{Interviewers: How does a project come about?}

SWB projects start either through a request, http:// community.amstat.org/statisticswithoutborders/gethel pwithanewproject or through SWB volunteers (usually Gary Shapiro or I) seeking out organizations to work with.

The conversation always starts with finding out about the organization, what projects they would like help on, if there are data restrictions (e.g., confidentiality statements), location restrictions (e.g., requirement to be on-site). This information will be developed into a draft request or "write-up".

Before a request for volunteers is sent out, the New Projects Coordinator will send the write-up to the organization and ask them if they approve of the wording of the request.

Some organizations request their name and website not be mentioned for confidentiality reasons. The request for volunteers will usually generate more than can be managed. Then, we have to send out another "Call" to say that the project is closed. However, there have been times where we need to send out a "rerequest for volunteers"; this is usually the case when very specific skill sets or requirements are being asked by the organization.

\section{Interviewers: What skills from your 'paid-work life' did you bring to your 'volunteer work life?' How do the work experiences mesh?}

I brought to my volunteer position, as I do with my work, the skills of organization, ability to work on a team, seeing the big-picture, communication of statistical skills and techniques to a non-technical population, and the curiosity to look at problems in a variety of ways. These are the skills that have helped me both in the professional realm as a New Projects Chair and Chair of SWB.

My first career was as a public school mathematics and statistics teacher. I am now working as a statistician in the area of Medicaid and Medicaid fraud for my second career.

\section{Interviewers: What are the responsibilities of the Chair of the New Project Committee?}

The job of New Projects Chair has expanded over the years. At the time I started as New Projects Chair, SWB had four or five projects a year. During my time as New Project Chair, SWB grew to having 24-30 projects a year. Close to the end of my tenure, Gary Shapiro worked with me on organizing a variety of projects; prior to that though, I was so overwhelmed with organizing projects, volunteers, etc, that I did not have the time to organize a committee. Gary Shapiro, now New Projects Chair, has re-organized the committee and has six co-chairs who work under him. This has dispersed the workload but he now also manages six people. Being on the New Projects Committee is more like being a consultant and a project organizer; you talk to the client to develop the over-all project definition, requirements (i.e., language, statistical skills, and software), final product goals, and time-frame.

\section{Interviewers: Does a request for help always work out?}

Not all requests for help are taken on. Sometimes it is because SWB does not have a volunteer with the 
specific skill set required. For example, there was a recent request for a statistician with a genome and horticultural background. Some people who request help do not understand that most SWB volunteers have full-time jobs and family obligations. Other requests have too many requirements given the time constraints. However, all requests are usually discussed at least between the New Projects Chair and the SWB Chair.

\section{Interviewers: What does it take to have a successful project?}

Communication and teamwork are the most essential skills. I have observed project leads who have worked with some difficult clients and projects but who have delivered a very professional final product to an eventual positive client. However, there have also been times even those skills do not help. In one project, the individual who headed the non-profit had had a few classes in statistics. She had already conducted the survey and wanted help analyzing the data. The SWB volunteers, two highly regarded statisticians, indicated that the methodology used to collect the data, and the statistical methods this individual insisted on using, were not valid to make the conclusions or answer the questions she wanted to answer. The project was not completed.

\section{Interviewers: Could you also describe the responsibilities of the Chair of SWB?}

Public relations, seeking new projects and organizations to work with, and developing a sustainable organization are the most challenging responsibilities as Chair. SWB has grown substantially and it is like running a small non-profit. The goals are to involve more members as volunteers, expand the number of projects we have, create both professional (e.g., Royal Statistician Society) and clientele (e.g., Digital Humanitarian Network) partnerships.

Interviewers: Recently, it was announced that SWB was the recipient of the Humanity Road's Da Vinci Award. Congratulations. This award is given to a patron or contributor who gave much needed support to the Humanity Road's programs. Tell us about the work that SWB did to receive this recognition.

Throughout this conversation, I have brought up developing a series of projects with Digital Humanitarian
Network, http://digitalhumanitarians.com/.

Technology and humanitarian relief efforts are not my area of expertise. However, Humanity Road, one of the non-profit organizations under the umbrella of the DHN, understood Statistics Without Borders could be of great benefit to the larger organization. Humanity Road requested SWB help on a project in which part of the outcome was to understand how both organizations could benefit from the other.

The project was post-crisis Typhoon Haiyan. (formed between Nov 3-11, 2013) 1 Humanity Road's goal was to look back at their response to Typhoon Haiyan, analyze the tweets data collected, and develop a manual on how Statistics Without Borders would work with Humanity Road during a crisis. Humanity Road published the product, a twenty-page guide and report that contains helpful information for emergency managers 2 All three SWB volunteers, Michiko Wolcott, project lead, Joseph Pollack, and Minh Tran, are cited as co-authors of the manual. (This work was one of the two 2014 medal winners] 3

The longer I volunteer with SWB, the more I like the organization. Overall, the volunteers are very professional and hard working. They give their time and talents for free. This says so much about the organization.

This concludes our Conversation on Statistics Without Borders with Cathy Furlong.

If you are interested in discussing possible projects with SWB, you can complete a form at http://communi ty.amstat.org/statisticswithoutborders/gethelpwithane wproject.

If you are interested in volunteering with Statistics Without Borders, you can find out more at: http:// community.amstat.org/statisticswithoutborders/getinv olved.

\footnotetext{
${ }^{1}$ https://en.wikipedia.org/wiki/Typhoon_Haiyan.

${ }^{2}$ More information on this project can be found in the June issue - C. Graham, C. Thompson, M. Wolcott, J. Pollack and M. Tran, A guide to social media emergency management analytics: Understanding its place through Typhoon Haiyan tweets, Statistical Journal of the IAOS 31(2) (2015), 227-236.

${ }^{3}$ In the award announcement, it describes the guide as follows: the guide "helps [emergency managers] identify and discuss relevant questions when planning their [Social Media Emergency Management] SMEM response." The announcement documents that emergency management is a well established field of study, however, the area of social media analytics is still quite new and even statisticians are still trying to navigate this field to figure out the opportunities for using statistics to help in a time of crisis. http://humanityroad. org/smemanalyticsguide/.
} 